\title{
The importance of ions in low pressure PECVD plasmas
}

\author{
Andrew Michelmore ${ }^{1 *}$, Jason D. Whittle ${ }^{1,2}$ and Robert D. Short ${ }^{1}$ \\ ${ }^{1}$ Mawson Institute, Division of IT, Engineering and the Environment, University of South Australia, Mawson Lakes, SA, Australia \\ ${ }^{2}$ School of Engineering, Division of IT, Engineering and the Environment, University of South Australia, Mawson Lakes, SA, Australia
}

\section{Edited by:}

Agnes Granier, Centre National de la Recherche Scientifique, France

Reviewed by:

Mikhail Shneider, Princeton

University, USA

Alan A Howling, Ecole

Polytechnique Fédérale de

Lausanne-CRPP, Switzerland

Rony Snyders, University of Mons,

Belgium

Lenka Zajicková, Masaryk University,

Czech Republic

*Correspondence:

Andrew Michelmore, Mawson

Institute, Building V, Mawson Lakes

Campus, University of South

Australia, Mawson Lakes, 5095, SA,

Australia

e-mail: andrew.michelmore@

unisa.edu.au
Plasma enhanced chemical vapor deposition (PECVD) can be used to fabricate surfaces with a wide range of physical and chemical properties and are used in a variety of applications. Despite this, the mechanisms by which PECVD films grow are not well understood. Moreover, the species which contribute to film growth can be considered quite differently depending on the process. Particularly for functionalized plasma polymer films, the growth mechanisms are considered with respect to the chemistry of the depositing species, ignoring the physics of plasmas. Here we analyse the role ions play in the deposition of three common classes of depositing plasmas, and how these closely related fields treat ions very differently.

Keywords: PECVD, ions, silanes, diamond-like carbon, plasma polymers

\section{INTRODUCTION}

While glow discharges were observed as early as 1796 [1] the term "plasma" was first coined by Irving Langmuir in 1928 [2]. Plasma discharges of reactive vapors were first reported as early as the 1930 [3], but research interest in plasma deposition started in the 1960s when the physical $[4,5]$ and chemical [6] properties of some organic plasma deposits were described. Modern plasma deposition techniques include magnetron sputtering [7], ion plating [8], pulsed laser deposition [9], and various plasma enhanced chemical vapor deposition (PECVD) techniques.

PECVD has found use in a wide variety of applications. For example silane plasmas are used in solar cells [10] and microelectronics [11], diamond-like carbon (DLC) coatings are used as hard, wear-resistant barriers for mechanical parts and biomedical implants [12], while soft functionalized plasma polymers may be used to attach biomolecules to surfaces for improved biocompatibility or drug delivery [13]. Recently, plasma deposition has enabled the convergence of technologies in the nano and micro scale range, including controlling interfacial bonding in composites [14], fabrication of nano-thin films for electronic applications $[15,16]$ and microscale features to control protein adsorption [17].

An important consideration in the growth of all of these types of coatings from plasma is the mechanisms by which film growth occurs (Figure 1). As plasma consists of a complex mixture of species with different masses, charges, chemical reactivities and kinetic energies, identifying the species which provide mass to the film can be difficult. However, as discussed later, these species can confer very different properties to the film due largely to the energy they provide to the surface. Therefore, an understanding of the growth mechanisms is crucial to tailoring film properties. One of the key plasma components are positively charged ions. This is because the electrical fields established by plasmas adjacent to surfaces provide ions with sufficient kinetic energy to promote chemical reactions, and therefore the ions are the engines which drive film growth (either directly or indirectly). The role that ions play though is understood in quite different ways depending on which field of PECVD is being discussed.

\section{DIAMOND-LIKE CARBON FILMS}

DLC films were first grown in 1971 [18] and are grown from plasmas of molecules such as methane, acetylene, or larger hydrocarbons. It has been known in this field for some time that the mechanical properties of the film are determined by the energy of the ions arriving at the surface [19]. Additionally, DLC films were originally grown from ion-beam deposition [20]. Therefore, ions have been considered to be important species in contributing mass to the film, and this led to early researchers in the field considering ions almost exclusively. More recently, the role of neutrals has been demonstrated. For example, both Richter et al. [21] and Moller [22] assumed a sticking probability of 1 for ions (probably an overestimate) and calculated for a range of precursors that ions contributed between 25 and $100 \%$ to the mass of the deposit, critically depending on the chemical structure of the precursor. As pointed out by Richter et al. [21] "despite the fact that most authors confine themselves to the ions, in principle both ionized species and neutral molecules must be taken into account as film-forming particles." Therefore, in the field of DLC films, ions and neutral species 
(intact precursor molecules and radicals) have been thought to be important mass-contributing species.

\section{SILANE FILMS}

Reports of films grown from $\mathrm{SiH}_{4}$ and related compounds and gas mixtures started appearing in the late 1960s [23]. The dominant species are often $\mathrm{SiH}_{\mathrm{x}}^{+}$, but also $\mathrm{SiH}_{\mathrm{x}}$ radicals. From early in the development of silane based films, both neutrals and ions were considered important $[24,25]$. Researchers in this field have studied the plasma phase mass spectra of both neutrals and ions [26] and controlled the ion energy to elucidate the role of $\mathrm{SiH}_{\mathrm{x}}$ radicals, $\mathrm{SiH}_{\mathrm{x}}^{+}$ions and even $\mathrm{H}^{+}$ions in the deposition process [27]. A strong dependence on the plasma pressure is observed with Perrin [28] demonstrating that the contribution of ions to the deposit varies between nearly $100 \%$ at $0.1 \mathrm{~Pa}$ down to around $1 \%$ at $100 \mathrm{~Pa}$.

\section{PLASMA POLYMER FILMS}

A number of fundamental papers on plasma polymer deposition were published in the late 1960s and early 1970s, including a number of studies looking at the mechanisms of deposition from plasma, including the roles of both ions [29, 30] and radicals [31]. Then in 1979, Shen and Bell [32] correctly showed that in weakly ionized plasmas the ratio of radicals to ions in the plasma phase is of the order of $10^{3}-10^{5}$. They followed this with a discussion on the role of radicals in mechanisms of deposition, ignoring any possible contribution from ions presumably because they believed the density of ions was so low that any mass deposited by ions would be insignificant. Then in Plasma Polymerization Yasuda [33] proposed the rapid step-growth polymerization mechanism (RSGP), which became the most cited work in the field. While Yasuda acknowledged that RSGP could proceed via any "chain-carrying species" (including radicals, ions and excited species), all the mechanisms subsequently discussed involved radicals exclusively. Thus, it was implied that ions provided energy to the surface through energetic collisions which enabled further reactions to occur [34], but their role in contributing mass to films was discounted. As discussed below, there is now growing experimental evidence to support ions playing a greater role in plasma polymer growth [35-37].

\section{PLASMA PHYSICS OF IONS}

Thus, it can be seen that these related fields approach the issue of ions in plasmas in quite different ways, and accordingly ascribe different importance to ions. In some cases this appears to be driven by historical development of the field. What has been overlooked in some of these studies is some basic physics of non-thermal plasmas. Tonks and Langmuir described the plasma phase as a region of space where the "densities of ions and electrons are high but substantially equal" [38]. This is the case in the bulk of non-thermal plasmas and the flux, J, of both neutrals and ions are governed by thermal motion.

$$
J=0.25 n \sqrt{\frac{8 \mathrm{kT}}{\pi \mathrm{m}}}
$$

where $n$ is the particle density, $\mathrm{k}$ is Boltzmann's constant, $\mathrm{T}$ is the absolute temperature and $\mathrm{m}$ is the particle mass.

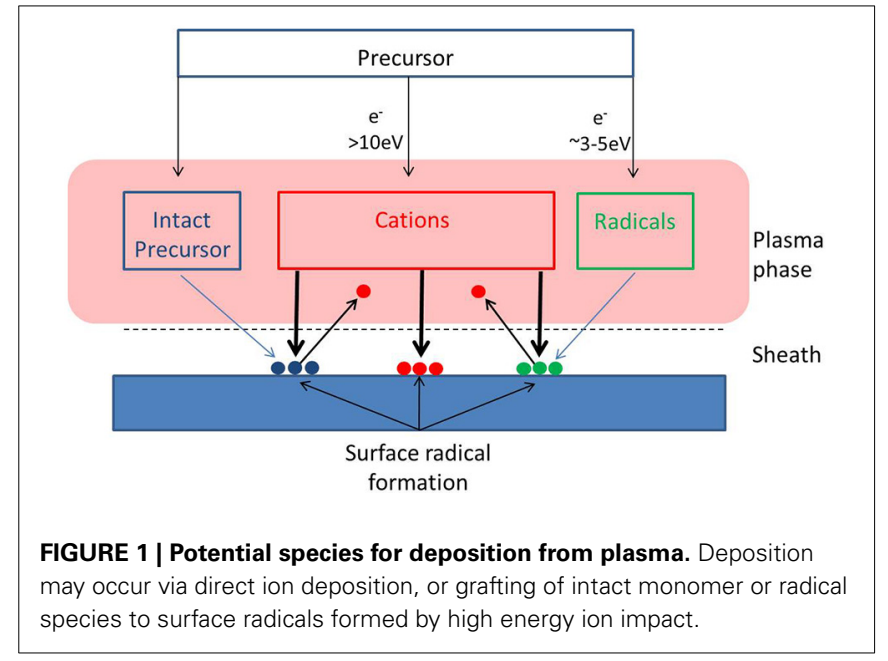

However, as early as 1949 David Bohm [39] described the effect of placing a surface in contact with a plasma phase. As electrons are lighter and hotter than positively charged ions, the flux of electrons to surfaces is initially much greater than that of the ions. This results in the surface gaining a negative potential relative to the plasma. The surface potential then develops until at equilibrium the flux of positive and negative charged species is equal. Bohm showed that the presence of the surface in the plasma results in the formation of a sheath region adjacent to the surface where the density of charged particles decreases. In fact, there are two distinct regions; the sheath, where the density of the positive ions is higher than that of electrons, and a pre-sheath, where the densities are the same but decrease slightly compared to the bulk plasma. In this pre-sheath region, ions are accelerated such that they enter the sheath at the Bohm velocity, $\mathrm{u}_{b}$

$$
\mathrm{u}_{\mathrm{b}}=\sqrt{\frac{\mathrm{kT}}{\mathrm{m}}}
$$

where $T_{e}$ is the electron temperature. The flux of ions, $\mathrm{J}_{\mathrm{i}}$, is then given by:

$$
J_{i}=\exp \left(-\frac{1}{2}\right) n_{i} \sqrt{\frac{k T_{e}}{m}}
$$

where $n_{\mathrm{i}}$ is the ion density in the plasma phase and the $\exp (-1 / 2)$ term describes the decrease in ion density in the pre-sheath.

Therefore, the surface has the effect of increasing the flux of positive ions through the pre-sheath/sheath regions to the surface. The increase in flux above the normal thermal flux, $J_{t}$, can be mathematically described by:

$$
\frac{J_{i}}{J_{t}}=\sqrt{2 \pi} \exp \left(-\frac{1}{2}\right) \sqrt{\frac{T_{e}}{T_{i}}}
$$

where $T_{\mathrm{i}}$ is the temperature of the ions in the plasma phase, usually close to ambient temperature. Therefore, for a typical electron temperature of $\sim 3 \mathrm{eV}$, the flux of ions is increased by a factor 
of $\sim 15$ [40]. It should be noted that for DC plasmas, this factor can be even higher [41]. Neutral species, such as radicals and intact precursor, are not accelerated to the surface due to the generation of potentials in the plasma, and so while the density ratio of radicals-to-ions may be of the order of $10^{4}$, the flux ratio, the important ratio for film growth, is substantially lower.

While this phenomenon is well known to plasma physicists, it is often overlooked in the field of depositing plasmas as it is assumed that depositing plasmas are governed by chemical processes [1]. Additionally, one of the assumptions in Bohm's calculations was that the sheath region is non-collisional; in some cases, particularly for silanes and plasma polymers where the pressure can be relatively high, this may not be the case which can affect the ion energy and structure [42].

\section{EXPERIMENTAL EVIDENCE}

While the increase in ion flux due to the electric fields generated decreases the neutral: ion flux ratio to around $10^{2}-10^{3}$, it cannot alone explain how ions can contribute significant mass to the deposit compared to neutrals. Recent experimental evidence shows that ions can be larger than neutrals due to reactions in the plasma phase, and that ions are much more likely to stick to the surface upon impact.

\section{PLASMA PHASE MASS SPECTROMETRY}

Analysis of the plasma phase has shown that ions can form large oligomers in the plasma phase. O'Toole et al. [43] demonstrated for organic precursors that ions form large molecules of the form $(n M+H)^{+}$, where $M$ is the precursor and $n$ is an integer up to 3. This was shown for acids [43], alcohols [44] and amine-containing organics [45]. Simultaneously, the neutral mass spectra were measured by electron impact and dimers were only observed for methyl isobutyrate. It has similarly been measured that silane plasmas exhibit $\mathrm{Si}_{2} \mathrm{H}_{\mathrm{x}}^{+}$and $\mathrm{SiCH}_{\mathrm{x}}^{+}$ions when combined with methane [24]. Thus, ion-molecule reactions in the plasma phase have been confirmed.

There is also experimental evidence of a correlation between the ionic plasma species observed and the chemistry of the deposit. Hexamethyldisiloxane plasmas exhibit ion precursor, dimer and trimer peaks; the same peaks are observed when measuring the surface chemistry by ToF-SIMS. The co-ordination of silicon and oxygen measured by XPS also correlates well with the ionic plasma species observed [37].

The mechanism by which large ions grow has been modeled by selected ion flow tube mass spectrometry, whereby a positively charged precursor ion, for example $(\mathrm{M}+\mathrm{H})^{+}$, is reacted with neutral $\mathrm{M}$ in a buffer gas and the products measured by mass spectrometry [46]. Reaction conditions were kept close to those in plasma (pressure, temperature) and the resultant product ions at $\sim 2 \mathrm{M}, 3 \mathrm{M}$ correlate with those directly seen in plasma. This has allowed some insight into the kinetics of plasma-phase ion-molecule reactions.

\section{STICKING PROBABILITY}

It is often assumed, particularly in DLC plasmas, that the sticking probability of ions is 1 . However, comparison with calculations for hyperthermal ions [35] shows that this assumed sticking probability is probably an overestimation. This study showed a more realistic sticking probability of between 20 and 50\%, and is dependent on the ion energy [37]. It should be noted that this is almost certainly a net sticking probability as ions with energies greater than $\sim 15 \mathrm{eV}$ can simultaneously sputter the growing film [47].

As ions usually have energy greater than $10 \mathrm{eV}$ when they arrive at the surface, they can provide enough kinetic energy to promote bond breakage and rearrangement [47]. Neutral species on the other hand rely on chemical energy to attach to the surface. In the case of plasma radicals, this requires that the radical arrive at the surface in the vicinity of an existing surface radical. It has been shown by von Keudell et al. [48] that the sticking probability of methyl radicals is extremely low at $\sim 3 \times 10^{-5}$, but this increases to $\sim 3 \times 10^{-3}$ in the presence of atomic hydrogen. They also showed that even a plasma radical colliding with a surface radical only results in a sticking probability of $\sim 50 \%$. This probability may be even lower for larger radical species as steric and collision orientation effects become important [49].

Combined, these analyses show that while the density of neutrals and radicals in the plasma phase may be extremely high relative to ions, the combination of increased flux due to sheath formation, plasma phase oligomerisation and higher ionic sticking probability demonstrates that both ions and neutrals should be considered as contributing mass to plasma deposits.

\section{IMPLICATIONS DEPOSITION KINETICS}

The role that ions plays in depositing plasmas compared to neutral species has a profound effect on the kinetics of deposition [43]. It has been shown that the deposition of saturated precursors is dominated by ionic processes while precursors which contain sites of unsaturation can deposit via neutral grafting [50]. There is a strong negative correlation between the degree of neutral grafting and fragmentation of the precursor in the plasma phase; thus for unsaturated precursors, neutral grafting dominates the kinetics at low plasma power and high pressure, but ionic processes increase in importance when the power is increased or the pressure decreased. Similar results have been shown for DLC films for methane and acetylene plasmas [51].

The contribution of ions to the deposition process also opens the possibility to control the kinetics using measureable plasma parameters, such as ion flux. This was first demonstrated in 1971 when the DC bias on the substrate was varied between +60 and $-350 \mathrm{~V}$ [29]. Applying a positive bias decreases the positive ion flux and ion energy and Westwood showed that at high enough bias, the deposition stopped (note that intact precursor and radical species could still diffuse to the substrate but no deposition was observed). Decreasing the bias resulted in a linear increase in deposition rate until-100 V when the deposition rate decreased again, presumably due to ion etching becoming important. Similarly, the flux of ions to substrates can be used as a process parameter to transfer plasma processes between reactors [52].

\section{FILM PHYSICAL AND MECHANICAL PROPERTIES}

It has been well known in the field of DLC plasmas that ions play the dominant role in determining the mechanical properties 
of films. Pappas and Hopwood [53] and Peter et al. [51] measured an increase in the film hardness for methane plasmas up to bias voltages of $\sim 200-300 \mathrm{~V}$, followed by a slight decrease at higher biases. For methane the trend was largely independent of pressure, however for acetylene the hardness decreased with increasing pressure. These results correlated with the contribution of ions to the deposit (methane $\sim 60 \%$, acetylene $\sim 20 \%$ ) and the ion energy flux to the film per deposited carbon atom. For silane plasmas, the role of ion energy in determining the crystallinity of the film has also been shown [27].

In the case of functional plasma polymers, the trends are less clearly defined. Hegemann et al. [54] for example showed that increasing the momentum flux density (dominated by ion contribution) resulted in densification of $\mathrm{NH}_{3} / \mathrm{C}_{2} \mathrm{H}_{4}$ copolymer films. Similarly, increasing the ratio of $\mathrm{NH}_{3}: \mathrm{C}_{2} \mathrm{H}_{4}$, and therefore decreasing the amount of unsaturated precursor in the plasma, resulted in denser films [55]. Conversely for lower energy density film formation, saturated precursors result in less dense films but with increased elastic modulus [56] due to high cross-linking. Typical ion energies for plasma polymer deposition are $10-50 \mathrm{eV}$, while for DLC plasma deposition the ion energy can be an order of magnitude higher. Even higher ion energies $(\sim 20 \mathrm{keV})$ can be utilized in plasma immersion ion implantation [57] which effect long lasting chemical changes to a depth of around $30 \mathrm{~nm}$. These studies highlight the key role ion energy plays in depositing plasmas.

\section{CONCLUDING REMARKS}

While the fields of DLC, silane and plasma polymer surface coatings share some similarities, the way they have approached the role of ions in deposition is quite different. In recent years there has been a slight convergence of ideas, with recognition by plasma polymer researchers that many plasma species, including ions, may contribute mass to surface coatings from plasma. The role that ions play is unique in that they not only can provide mass, but also dramatically affect the chemical and physical properties of the film due to their high energy. Further understanding of the role of ions in this regard will help develop better films and control of plasma polymer processes in the future.

\section{REFERENCES}

1. Friedrich J. Mechanisms of plasma polymerization - reviewed from a chemical point of view. Plasma Processes Polym. (2011) 8:783-802. doi: 10.1002/ppap.201100038

2. Langmuir I. Oscillations in ionized gases. Proc Natl Acad Sci USA. (1928) 14:627-37. doi: 10.1073/pnas.14.8.627

3. Linder EG, Davies AP. Reactions of hydrocarbons in the glow discharge. J Phys Chem. (1930) 35:3649-72. doi: 10.1021/j150330a017

4. Goodman J. The formation of thin polymer films in the gas discharge. J Polym Sci. (1960) 44:551-2. doi: 10.1002/pol.1960.1204414428

5. Williams T, Hayes MW. Polymerization in a glow discharge. Nature (1966) 209:769-73. doi: 10.1038/209769a0

6. Jesch K, Bloor JE, Kronick PL. Structure and physical properties of glow discharge polymers. I. Polymers from hydrocarbons. J Polym Sci A-1 Polym Chem. (1966) 4:1487-97.

7. Kelly PJ, Arnell RD. Magnetron sputtering: a review of recent developments and applications. Vacuum (2000) 56:159-72. doi: 10.1016/S0042207X(99)00189-X

8. Aisenberg S, Chabot RW. Physics of ion plating and ion beam deposition. J Vac Sci Technol. (1973) 10:104-7. doi: 10.1116/1.1317915
9. Chrisey DB, Pique A, McGill RA, Horwitz JS, Ringeisen BR, Bubb DM, et al. Laser deposition of polymer and biomaterial films. Chem Rev. (2003) 103:553-76. doi: 10.1021/cr010428w

10. Cheng Q, Xu S, Ostrikov K. Temperature-dependent properties of nc-Si thin films synthesized in low-pressure, thermally nonequilibrium, high-density inductively coupled plasmas. J Phys Chem C (2009) 113:14759-64. doi: $10.1021 /$ jp9047083

11. Kessels WMM, McCurdy PR, Williams KL, Barker GR, Venturo VA, Fisher ER. Surface reactivity and plasma energetics of $\mathrm{SiH}$ radicals during plasma deposition of silicon-based materials. J Phys Chem B (2002) 106:2680-9. doi: $10.1021 /$ jp013895q

12. Beard JD, Aleksandrov S, Walker CH, Wolverson D, Mitchels JM, Gordeev SN. Magnetically enhanced plasma coating of nanostructures with ultrathin diamond-like carbon films. RSC $A d v$. (2014) 4:26635-44. doi: $10.1039 / \mathrm{c} 4 \mathrm{ra02841d}$

13. Siow KS, Britcher L, Kumar S, Griesser HJ. Plasma methods for the generation of chemically reactive surfaces for biomolecule immobilization and cell colonization - a review. Plasma Processes Polym. (2006) 3:392-418. doi: 10.1002/ppap.200600021

14. Lopattananon N, Kettle AP, Tripathi D, Beck AJ, Duval E, France RM, et al Interface molecular engineering of carbon-fiber composites. Compos A (1999) 30:49-57.

15. Jacob MV, Bazaka K, Weis M, Taguchi D, Manaka T, Iwamoto M. Fabrication and characterization of polyterpenol as an insulating layer and incorporated organic field effect transistor. Thin Solid Films (2010) 518:6123-9. doi: 10.1016/j.tsf.2010.06.014

16. Bhattacharyya D, Yoon W-J, Berger PR, Timmons RB. Plasma-polymerized multistacked organic bipolar films: a new approach to flexible high-k dielectrics. Adv Mater. (2008) 20:2383-8. doi: 10.1002/adma.200702981

17. Menzies DJ, Gengenbach G, Forsythe JS, Birbilis N, Johnson G, Charles C, et al. One step multifunctional micropatterning of surfaces using asymmetric glow discharge plasma polymerization. Chem Commun. (2012) 48:1907-9. doi: $10.1039 / \mathrm{c} 2 \mathrm{cc} 15578 \mathrm{~h}$

18. Aisenberg S, Chabot R. Ion-beam deposition of thin films of diamond-like carbon. J Appl Phys. (1971) 42:2953. doi: 10.1063/1.1660654

19. Grill A. Diamond-like carbon: state of the art. Diam Relat Mater. (1999) 8:428-4.

20. Robertson J. Diamond-like amorphous carbon. Mater. Sci. Eng R (2002) 37:129-281. doi: 10.1016/S0927-796X(02)00005-0

21. Richter F, Schaarschmidt G, Franke D-W, Wallendorf T, Rau B. Analysis of the growth process of a-C:H layers. Diam Relat Mater. (1993) 2:1344-9.

22. Moller W. Plasma and surface modeling of the deposition of hydrogenated carbon films from low-pressure methane plasmas. Appl Phys A Solids Surf. (1993) 56:527-46. doi: 10.1007/BF00331402

23. Weinreich OA, Ribner A. Optical and electrical properties of SiC films prepared in a microwave discharge. J Electrochem Soc. (1968) 115:1090-2. doi: $10.1149 / 1.2410892$

24. Catherine Y, Turban G, Grolleau B. Reaction mechanisms in plasma deposition of SixC1-x:H films. Thin Solid Films (1981) 76:23-33. doi: 10.1016/00406090(81)90062-6

25. Kushner MJ. Plasma chemistry of $\mathrm{He} / \mathrm{O}_{2} / \mathrm{SiH}_{4}$ and $\mathrm{He} / \mathrm{N}_{2} \mathrm{O} / \mathrm{SiH}_{4}$ mixtures for remote plasma-activated chemical-vapor deposition of silicon dioxide. J Appl Phys. (1993) 74:6538-53. doi: 10.1063/1.355115

26. Moiseev T, Chrastina D, Isella G. Plasma composition by mass spectrometry in a $\mathrm{Ar}-\mathrm{SiH}_{4}-\mathrm{H}_{2}$ LEPECVD process during nc-Si deposition. Plasma Chem Plasma Process. (2011) 31:157-74. doi: 10.1007/s11090-010-9277-9

27. Bruneau B, Wang J, Dornstetter J-C, Johnson EV. Growth mechanisms study of microcrystalline silicon deposited by $\mathrm{SiH}_{4} / \mathrm{H}_{2}$ plasma using tailored voltage waveforms. J Appl Phys. (2014) 115:084901. doi: 10.1063/1.4866693

28. Perrin J. Plasma and surface reactions during a-Si:H film growth. J Non Cryst Solids (1991) 137-8:639-44.

29. Westwood AR. Glow discharge polymerization- rates and mechanisms of polymer formation. Eur Polym J. (1971) 7:363-75. doi: 10.1016/00143057(71)90007-3

30. Morris J, Charlesby A. An investigation of the polymerization of styrene initiated by glow discharge. Eur Polym J. (1966) 2:177-84. doi: 10.1016/00143057(66)90039-5

31. Denaro AR, Owens PA, Crawshaw A. Glow discharge polymerization - styrene. Eur Polym J. (1968) 4:93-106. doi: 10.1016/0014-3057(68)90010-4 
32. Shen M, Bell AT. A review of recent advances in plasma polymerization. In: Shen M, editor. Plasma Polymerization. ACS Symposium Series. Washington, DC: American Chemical Society (1979). p. 1-33. doi: 10.1021/bk-1979-0108

33. Yasuda H. Plasma Polymerization. New York: Academic Press (1985).

34. Yasuda H, Hsu T. Some aspects of plasma polymerization investigated by pulsed RF discharge. J Polym Sci Polym Chem Ed. (1977) 15:81-97. doi: 10.1002/pol.1977.170150109

35. Brookes PN, Fraser S, Short RD, Hanley L, Fuoco E, Roberts A, et al. The effect of ion energy on the chemistry of air-aged polymer films grown from the hyperthermal polyatomic ion $\mathrm{Si}_{2} \mathrm{OMe}_{5}^{+}$. Electron Spectros Relat Phenom. (2001) 121:281-97. doi: 10.1016/S0368-2048(01)00340-1

36. Choukourov A, Kousal J, Slavinska D, Biederman H, Fuoco ER, Tepavcevic $S$, et al. Growth of primary and secondary amine films from polyatomic ion deposition. Vacuum (2004) 75:195-205. doi: 10.1016/j.vacuum.2004. 02.006

37. Michelmore A, Bryant PM, Steele DA, Vasilev K, Bradley JW, Short RD. Role of ions in determining the deposition rate and film chemistry of continuous hexamethyl disilioxane plasmas. Langmuir (2011) 27:11943-50. doi: 10.1021/la202010n

38. Tonks L, Langmuir I. Oscillations in ionized gases. Phys Rev. (1929) 33:195-211. doi: 10.1103/PhysRev.33.195

39. Bohm D. Minimum ionic kinetic energy for a stable sheath. In: Guthrie A and Wakerling RK, editors. The Characteristics of Electrical Discharges in Magnetic Fields. New York; London: McGraw Hill (1949). p. 77-86.

40. Michelmore A, Steele DA, Whittle JD, Bradley JW, Short RD. Nanoscale deposition of chemically functionalised films via plasma polymerisation. RSC Adv. (2013) 3:13540-57. doi: 10.1039/c3ra41563e

41. Chapman B. Glow Discharge Processes. Chichester: John Wiley and Sons (1980).

42. d'Agostino R, Palumbo F. Comment on "Ion-Assisted Processes of Polymerization in Low-Pressure Plasmas." Plasma Processes Polym. (2012) 9:844-9. doi: 10.1002/ppap.201200072

43. O'Toole L, Beck AJ, Ameen AP, Jones FR, Short RD. Mass spectrometry of and deposition-rate measurements from radiofrequency-induced plasmas of methyl isobutyrate, methyl methacrylate and n-butyl methacrylate. J Chem Soc Faraday Trans. (1995) 91:1363-70. doi: 10.1039/ft9959 101363

44. O'Toole L, Short RD. An investigation of the mechanisms of plasma polymerisation of allyl alcohol. J Chem Soc Faraday Trans. (1997) 93:1141-5.

45. Beck AJ, Candan S, Short RD, Goodyear A, Braithwaite NJS. The role of ions in the plasma polymerization of allylamine. J Phys Chem. B (2001) 105:5730-6. doi: 10.1021/jp0043468

46. Mayhew CA, Short, RD. Selected ion flow tube studies to investigate the formation of acrylic and propionic acid protonated clusters in low power, low pressure RF plasmas. Chem Commun. (2009) 6:659-61. doi: 10.1039/ b815290j

47. Jacobs DC. Reactive collisions of hyperthermal energy molecular ions with solid surfaces. Annu Rev Phys Chem. (2002) 53:379-407. doi: 10.1146/annurev.physchem.53.100301.131622
48. von Keudell A, Schwartz-Selinger T, Meier M, Jacob W. Direct identification of the synergism between methyl radicals and atomic hydrogen during growth of amorphous hydrogenated carbon films. Appl Phys Lett. (2000) 76:676-8. doi: $10.1063 / 1.125858$

49. IUPAC. Compendium of Chemical Terminology, 2nd Edn. (the "Gold Book"). Compiled by A. D. McNaught and A. Wilkinson. Oxford: Blackwell Scientific Publications (1997).

50. Michelmore A, Gross-Kosche P, Al-Bataineh SA, Whittle JD, Short RD. On the effect of monomer chemistry on growth mechanisms of nonfouling PEG-like plasma polymers. Langmuir (2013) 29:2595-601. doi: 10.1021/la304713b

51. Peter S, Graupner K, Grambole D, Richter F. Comparative experimental analysis of the a-C:H deposition processes using $\mathrm{CH}_{4}$ and $\mathrm{C}_{2} \mathrm{H}_{2}$ as precursors. $J$ Appl Phys. (2007) 102:053304. doi: 10.1063/1.2777643

52. Michelmore A, Charles C, Boswell RW, Short RD, Whittle JD. Defining plasma polymerization: new insight into what we should be measuring. ACS Appl Mater Interfaces (2013) 5:5387-91. doi: 10.1021/am401484b

53. Pappas DL, Hopwood J. Deposition of diamondlike carbon using a planar radio frequency induction plasma. J Vac Sci Technol A (1994) 12:1576-82. doi: $10.1116 / 1.579358$

54. Hegemann D, Korner E, Blanchard N, Drabik M, Guimond S. Densification of functional plasma polymers by momentum transfer during film growth. Appl Phys Lett. (2012) 101:211603. doi: 10.1063/1.4767999

55. Guimond S, Hanselmann B, Amberg M, Hegemann D. Plasma functionalization of textiles: specifics and possibilities. Pure Appl Chem. (2010) 82:1239-45. doi: 10.1351/PAC-CON-09-10-38

56. Michelmore A, Steele DA, Robinson DE,Whittle JD, Short RD. The link between mechanisms of deposition and the physico-chemical properties of plasma polymer films. Soft Matter (2013) 9:6167-75. doi: 10.1039/c3sm51039e

57. Bilek MMM, Bax DV, Kondyurin A, Yin Y, Nosworthy NJ, Fisher K, et al Free radical functionalization of surfaces to prevent adverse responses to biomedical devices Proc Natl Acad Sci USA. (2009) 108:14405-10. doi: 10.1073/pnas. 1103277108

Conflict of Interest Statement: The authors declare that the research was conducted in the absence of any commercial or financial relationships that could be construed as a potential conflict of interest.

Received: 10 October 2014; accepted: 16 January 2015; published online: 04 February 2015.

Citation: Michelmore A, Whittle JD and Short RD (2015) The importance of ions in low pressure PECVD plasmas. Front. Phys. 3:3. doi: 10.3389/fphy.2015.00003

This article was submitted to Plasma Physics, a section of the journal Frontiers in Physics.

Copyright (c) 2015 Michelmore, Whittle and Short. This is an open-access article distributed under the terms of the Creative Commons Attribution License (CC BY). The use, distribution or reproduction in other forums is permitted, provided the original author(s) or licensor are credited and that the original publication in this journal is cited, in accordance with accepted academic practice. No use, distribution or reproduction is permitted which does not comply with these terms. 